\title{
Article \\ Evaluation of Ultrasound Accuracy in Acute Appendicitis Diagnosis
}

\author{
Magbool Alelyani ${ }^{1, *}$, Ibrahim Hadadi ${ }^{1}$, Nasser Shubayr ${ }^{2,3}{ }^{\mathbb{D}}$, Yazeed Alashban ${ }^{4} \mathbb{D}$, Mohammed Alqahtani $^{1}$, \\ Mohamed Adam ${ }^{1}$, Hajar Almater ${ }^{1}$ and Sultan Alamri ${ }^{5}$
}

1 Department of Radiological Sciences, College of Applied Medical Sciences, King Khalid University, Abha 61421, Saudi Arabia; ihadadi@kku.edu.sa (I.H.); mosalqhtani@kku.edu.sa (M.A.); madam@kku.edu.sa (M.A.); 437804506@kku.edu.sa (H.A.)

2 Diagnostic Radiology Department, College of Applied Medical Sciences, Jazan University, Jazan 45142, Saudi Arabia; nshubayr@jazanu.edu.sa

3 Medical Research Center, Jazan University, Jazan 45142, Saudi Arabia

4 Department of Radiological Sciences, College of Applied Medical Sciences, King Saud University, Riyadh 11362, Saudi Arabia; Yalashban@ksu.edu.sa

5 Department of Radiological Sciences, College of Applied Medical Sciences, Taif University, Taif 21944, Saudi Arabia; s.alamri@tu.edu.sa

* Correspondence: maalalyani@kku.edu.sa

check for updates

Citation: Alelyani, M.; Hadadi, I.; Shubayr, N.; Alashban, Y.; Alqahtani, M.; Adam, M.; Almater, H.; Alamri, S. Evaluation of Ultrasound Accuracy in Acute Appendicitis Diagnosis. Appl. Sci. 2021, 11, 2682. https://doi.org/ 10.3390/app11062682

Academic Editor: Francesco Bianconi

Received: 9 February 2021

Accepted: 15 March 2021

Published: 17 March 2021

Publisher's Note: MDPI stays neutral with regard to jurisdictional claims in published maps and institutional affiliations.

Copyright: (c) 2021 by the authors. Licensee MDPI, Basel, Switzerland. This article is an open access article distributed under the terms and conditions of the Creative Commons Attribution (CC BY) license (https:/ / creativecommons.org/licenses/by/ $4.0 /)$.

\begin{abstract}
Acute appendicitis it a quite common abdominal disorder and considered as a difficult diagnosis. An accurate diagnosis is essential to prevent any complication from delayed surgical intervention. Aim: To evaluate the diagnostic accuracy of ultrasound in acute appendicitis cases in Saudi Arabia compared with histopathology. Moreover, to determine whether there is a correlation between the accuracy of ultrasound in acute appendicitis and the sonographers' expertise. Methods: A retrospective study was conducted, including patients who admitted to the emergency room with clinical symptoms of suspected acute appendicitis and underwent ultrasound examinations. Diagnostic features, including diameter of the appendix $\geq 7 \mathrm{~mm}$, free fluid, lack of compressibility, no appendix seen, normal appearance, and thick wall, were recorded for each patient. Results: Only 61 of the 132 patients in the study were accurately diagnosed with the use of ultrasound. Just 44 of them were diagnosed with appendicitis (true positives) and 17 without appendicitis (true negatives). However, 69 patients who had positive histopathologic results received a negative ultrasound diagnosis (false negatives), and 2 patients with negative histopathologic findings had a positive ultrasound diagnosis (false positives). There was no significant association between the accuracy of the ultrasound diagnosis and the years of experience of the sonographers. Conclusion: a low level of diagnostic accuracy was demonstrated when utilizing ultrasound to diagnose cases of acute appendicitis. In addition, no association was found between the years of experience of the sonographer conducting the examination and the diagnosis of acute appendicitis.
\end{abstract}

Keywords: acute appendicitis; diagnosis accuracy; abdominal ultrasound; sonographers

\section{Introduction}

Acute appendicitis it a quite common abdominal disorder with a lifetime incidence of $7 \%$ [1]. Based on clinical and laboratory data, acute appendicitis is considered as a difficult diagnosis and can mimic various medical conditions of urologic, gastrointestinal, or gynecologic origin [2,3]. In pregnant patients, misdiagnosis and unneeded laparotomy may lead to sever complications and have detrimental consequences on fetal outcome [4]. The degree of inflammation can lead to inconsistent clinical presentation. It has been reported that the perforation risk in acute appendicitis can increase by $5 \%$ every $12 \mathrm{~h}$, meaning that an appendectomy should be performed no later than $36 \mathrm{~h}$ after a diagnosis of acute appendicitis is confirmed [5]. Therefore, any delay in diagnosis can lead to adverse 
effects such as perforation and wound abscesses [6]. On the other hand, mortality rate caused by acute appendicitis is reported to be about $0.25 \%$ taking into account all age groups [7-9]. A diagnostic approach that is only based on the patient's history and a clinical examination will lead to negative appendectomy rates of between $16 \%$ and $47 \%$. However, that figure drops to between $6 \%$ and $10 \%$ when medical imaging modalities are used in the diagnostic process [10]. Therefore, an accurate diagnosis is essential to prevent any complication from delayed surgical intervention.

The diagnostic accuracy for a wide variety of diseases has been improved significantly by imaging modalities. Computed tomography (CT) is the most specific and sensitive for diagnosing appendicitis [11]. However, CT uses significant amounts of ionizing radiation and has some limitations when imaging children and pregnant women [12]. A non-ionizing imaging technique such as ultrasound (US) can be used instead. In children, using US showed a substantial drop in negative appendectomy rates [13]. The importance of this is in reducing patient exposure to ionizing radiation, particularly in children. US has become increasingly popular as a diagnostic modality since it first became available for diagnosing appendicitis during the 1980s [14,15]. There are several benefits associated with using US as a diagnostic technique, including safety (no ionizing radiation), low cost, and real-time imaging [16]. However, graded compression ultrasonography has shown different levels of accuracy for diagnosing patients suspected of acute appendicitis. The sensitivity and specificity results range from $44 \%$ to $100 \%$ and $47 \%$ to $99 \%$, respectively. The experience and skill level of the sonographer may account for this variability [17].

The study aimed to evaluate the diagnostic accuracy of US in acute appendicitis cases in a central hospital in Saudi Arabia compared with histopathology, which is the current gold standard and to determine whether there is an association between the accuracy of US in acute appendicitis and the sonographers' expertise.

\section{Materials and Methods}

\subsection{Patients}

This observational, retrospective, hospital-based cross-sectional study was conducted in Saudi Arabia between February 2019 and December 2020. The study included patients who admitted to the emergency room with clinical symptoms of suspected acute appendicitis and underwent US examinations. Each patient's age, sex, sonography report and histopathological results were retrieved from their medical records. The elapsed time between the US examination and the surgery was not recorded.

\subsection{Medical Staff}

Emergency physicians referred patients with clinical symptoms of suspected acute appendicitis to the radiology department where sonographers perform sonography under supervision of the radiologists who prepare the sonography reports. Based on the clinical symptoms and the sonography report, surgeons were authorized to decide whether a patient needed to be immediately transferred to the operating room or could stay for observation.

\subsection{US Procedure}

All US examinations were performed using Philips iU22 or xMATRIX (Philips, Seattle, WA, USA) US scanners. Either a curvilinear transducer (at 3.5 MHz) or a linear transducer (at 5-7 MHz) was used, depending on the patient's weight, and a graded compression technique was used to diagnose appendicitis. Diagnostic features, including diameter of the appendix $\geq 7 \mathrm{~mm}$, free fluid, lack of compressibility, no appendix seen, normal appearance, and thick wall, were recorded for each patient.

\subsection{Histopathological Results}

The histopathological results for each subject were retrieved from their medical records. The histopathology test was performed after they had surgery. The histopathology test 
involved both macroscopic and microscopic examinations of the surgically-removed appendix. The features assessed included signs of acute inflammation, chronic inflammation, and luminal obstruction.

\subsection{Data Analysis}

The descriptive statistics of frequency and percentage were used to summarize the data. We calculated the diagnostic accuracy measures as follows: sensitivity (ability to correctly report images with appendicitis), specificity (ability to correctly classify images without appendicitis as being normal), PPV (probability that the appendicitis is present when the test is positive), NPV (probability that the appendicitis is not present when the test is negative), and accuracy (overall probability that a patient is correctly diagnosed). Then, the Chi-square test for independent samples was used to determine the association between the socio-demographic characteristics (sex and age) of the subjects, the years of experience of the sonographer, and the accuracy of the diagnosis. We then divided the sonographers into three subgroups based on their expertise and compared between their diagnostic performances (sensitivity and specificity) using the Chi-square test. A bar chart for the specificity and sensitivity of US was plotted against the various US features that were used for the diagnosis of acute appendicitis. A boxplot was used to demonstrate the relationship between the age of the subjects and the US features. The data were analyzed at 95\% confidence interval using Statistical Package for the Social Sciences (SPSS) Version 24 (IBM Corporation, Armonk, NY, USA).

\section{Results}

The study included 132 patients. The majority of the patients (59.8\%) were within the age range of 21-40 years. (Table 1) shows socio-demographic characteristics of the patients and accuracy of the US diagnosis. There was no significant association between the accuracy of the US diagnosis and the sex $(p=0.42)$ and age $(p=0.4)$ of the subjects.

Table 1. Socio-demographic characteristics of the patients and accuracy of the ultrasound diagnosis.

\begin{tabular}{ccc}
\hline & Number of Patients (\%) & Number of Accurate Diagnosis (\%) \\
\hline Sex & & \\
Male & $48(36.4 \%)$ & $20(32.8 \%)$ \\
Female & $84(63.6 \%)$ & $41(67.2 \%)$ \\
\hline Age range & & \\
$1-20$ & $37(28 \%)$ & $18(48.6 \%)$ \\
$21-40$ & $79(59.8 \%)$ & $36(47.4 \%)$ \\
$41-60$ & $7(5.3 \%)$ & $4(50 \%)$ \\
$61-80$ & $7(5.3 \%)$ & $1(14.3 \%)$ \\
$81-100$ & $1(0.76 \%)$ & $0(0.0 \%)$ \\
\hline
\end{tabular}

No significant association between the accuracy of the US and the sex and age of the subjects.

Only 61 of the 132 patients in the study were accurately diagnosed with the use of ultrasound. Just 44 of them were diagnosed with appendicitis (true positives) and 17 without appendicitis (true negatives). However, 69 patients who had positive histopathologic results received a negative US diagnosis (false negatives), and 2 patients with negative histopathologic findings had a positive US diagnosis (false positives). The analysis revealed that the sensitivity of the US was $38.9 \%$ (95\% CI 29.9 to 48.5 ), the specificity was $89.5 \%$ (95\% CI 66.8 to 98.7 ), the positive predictive values (PPV) was 95.7\% (95\% CI 85.3 to 98.8), and the negative predictive values (NPV) was $19.8 \%$ (95\% CI 16.6 to 23.4). The overall diagnostic accuracy was $46.2 \%$ (95\% CI 37.5 to 55$)$. The features of the 2 subjects that were incorrectly diagnosed as positive (false positive) included diameter $\geq 7 \mathrm{~mm}$ (1 patient) and free fluid (1 patient), and both patients were female.

(Table 2) shows differences in expertise (years) of sonographers and their diagnostic performances in diagnosing appendicitis. Sensitivity and specificity were found to be not significantly different between all subgroups. A comparison performed between the true 
and false US diagnoses against the ultrasound features that were used for the diagnosis reported by the sonographers. These US features were divided into six categories and checked against the histopathology diagnoses (Table 3).

Table 2. The expertise of sonographers and their diagnostic performance in diagnosing appendicitis.

\begin{tabular}{ccc}
\hline Experience & Sensitivity (\%) & Specificity (\%) \\
\hline$<10$ years & $36 \%$ & $83.3 \%$ \\
$10-19$ years & $31 \%$ & $89 \%$ \\
$>20$ years & $52 \%$ & $100 \%$ \\
\hline
\end{tabular}

Chi-square test showed no significant differences between subgroups in sensitivity and specificity.

Table 3. Ultrasound findings for appendicitis diagnoses.

\begin{tabular}{ccc}
\hline Imaging Feature & Accurate $\mathbf{( N = 6 1 )}$ & Missed $\mathbf{( N = 7 1 )}$ \\
\hline Diameter $\geq 7 \mathrm{~mm}$ & 17 & 6 \\
Free fluid & 28 & 25 \\
Lack of compressibility & 5 & 7 \\
No appendix seen & 7 & 24 \\
Normal appearance & 2 & 7 \\
Other & 2 & 2 \\
\hline
\end{tabular}

Evaluation of sensitivity, specificity, and age (years) against the US image features was performed. These features were categorized into six main categories using a thematic approach, and checked against the histopathology diagnosis as shown in Figures 1-3.

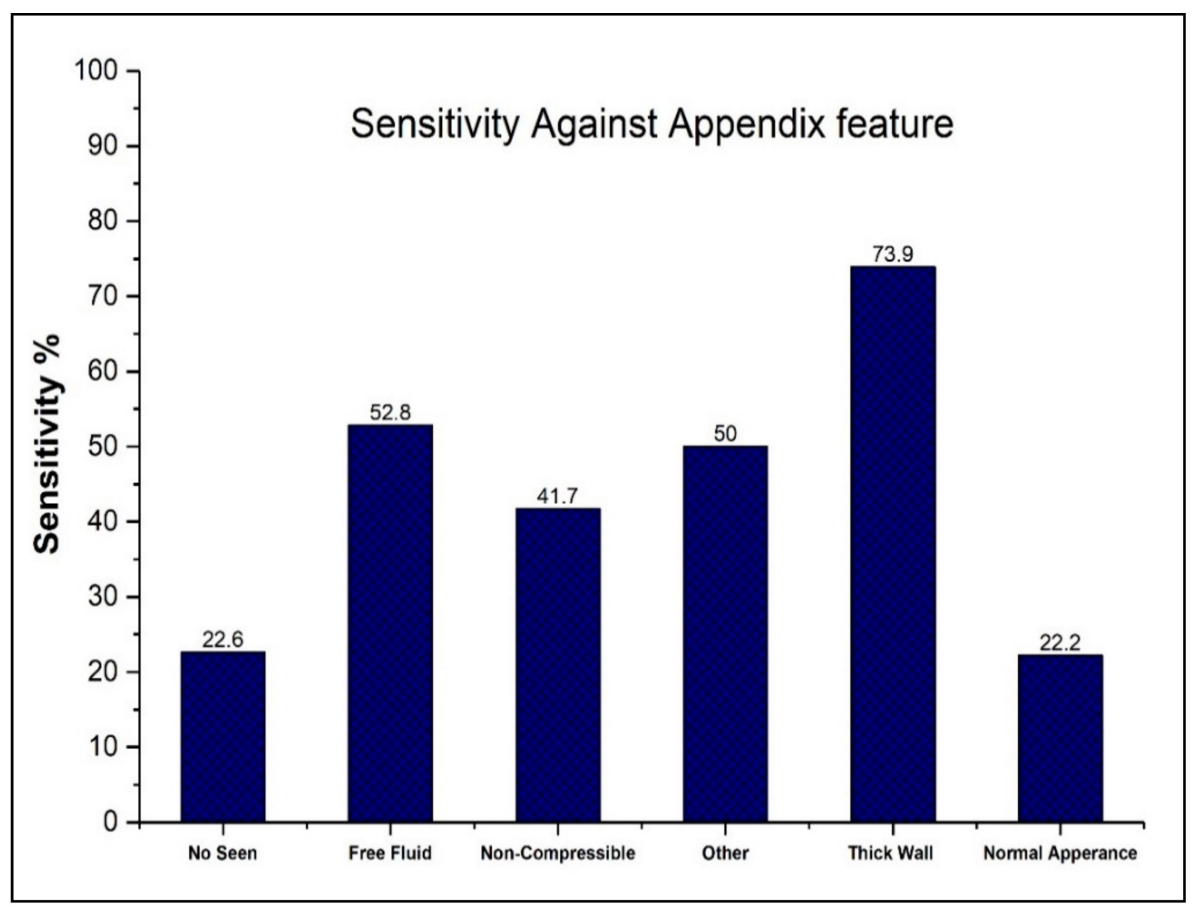

Figure 1. Sensitivity readings against image features. 


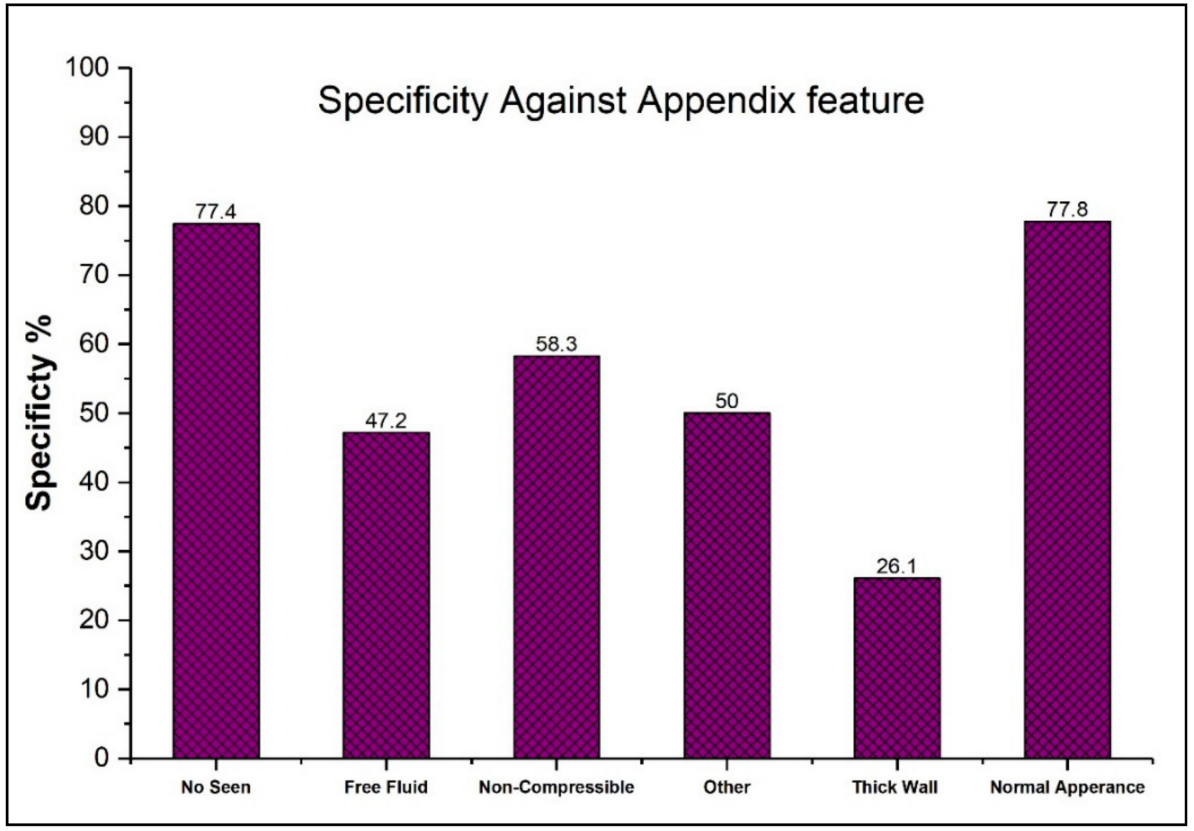

Figure 2. Specificity readings against image features.

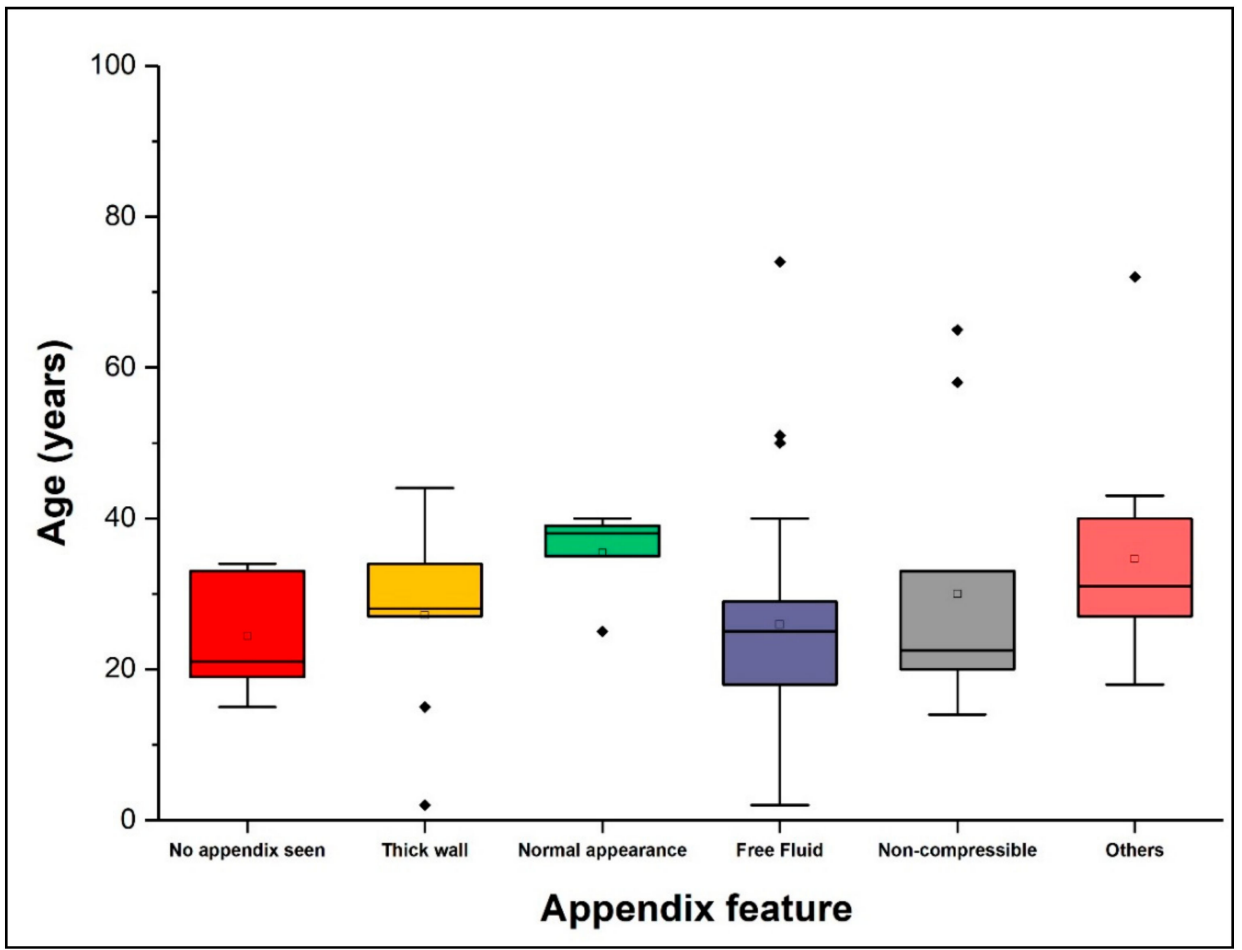

Figure 3. Boxplot illustrating the relationship between patients' age and image features. The black dots represent data outliers.

\section{Discussion}

US has been touted as an examination that may help in the diagnosis of acute appendicitis in addition to physical examination [18]. Furthermore, the non-ionizing characteristics of US have led to an increased interest in exploring its diagnostic accuracy for acute appendicitis. The only drawback in the choice of US as a diagnostic strategy is the concern about its diagnostic accuracy as explored in this study.

In this context, the graded compression US has been reported to demonstrate highly variable levels of accuracy. In particular, its sensitivity has been recorded as ranging 
between $44 \%$ and $100 \%$, and its specificity between $47 \%$ and $99 \%$ [17]. However, it has also been reported that the sensitivity of US can be as high as $90 \%$ if the diagnosis is made by an individual with a high level of expertise in the field [19].

In the present study, the sensitivity of US for diagnosing acute appendicitis was $38.9 \%$, and the specificity was $89.5 \%$. The study also demonstrated that there was no significant association between the accuracy of US diagnosis and the years of experience of the sonographers. A mere $46.2 \%$ of the patients in this study were correctly diagnosed.

According to D'Souza et al., the appendix is not commonly visualized by US, as US demonstrates insufficient sensitivity for diagnosing appendicitis [20]. During the current study, the visualization of the appendix was not possible in $21.8 \%$ of cases, and the number of false-negative cases was 24 out of a total 31 subjects.

The appendix is not detectable by US when located retrocecally or deep inside the pelvis. In addition, excessive overlying bowel gas may also impede the detection of appendicitis. The diagnosis is also dependent on the expertise of the sonographer conducting the procedure $[7,21,22]$. Conversely, our findings provide no evidence that the years of experience improve sonographer's performance in diagnosing appendicitis.

Lee et al. reported that the rate of negative appendectomies is $16 \%$ [23]. This study reported a much lower rate of negative appendectomies, with only $1.4 \%$ of cases being false positives. In contrast, Summa et al. reported that $2.2 \%$ of appendicitis diagnoses were false positives [22], while Al-Ajerami reported a figure of 4.4\% [24].

Several factors can influence the acute appendicitis diagnosis by US, the most crucial of which is the outer diameter of the vermiform appendix. In a previous study, a sensitivity of $97 \%$ and a PPV of $97 \%$ was noted when the outer diameter of the vermiform appendix was $7 \mathrm{~mm}$ or more; however, it also showed a high rate of false positives. Insufficient compressibility can also influence diagnosis, and levels of $85 \%$ sensitivity and 93\% PPV have been reported as a result [25].

During this study, an accurate diagnosis was made using US when the diameter of the vermiform appendix was $7 \mathrm{~mm}$ or more, leading to a sensitivity of $74 \%$ and a PPV of 93.3\% (See Figure $4 a, b$ ). The presence of free fluid also afforded a sensitivity of 53\% and a PPV of 95\% (See Figure 4c). The presence of free fluid is widely known as a secondary feature, and it could often be suggestive of an abdominal condition but not specific for appendicitis [26,27]. In this study, approximately 50\% of cases presented free fluid showed an absence of a distinctly visualized appendix. Therefore, radiologists argue that the appendix must be seen to confirm the inflammation. Nevertheless, the visualization of the appendix can often be difficult. It has been found that repeating ultrasound examination for secondary features after a few hours is necessary. It significantly improved ultrasound sensitivity and patient's management [28].

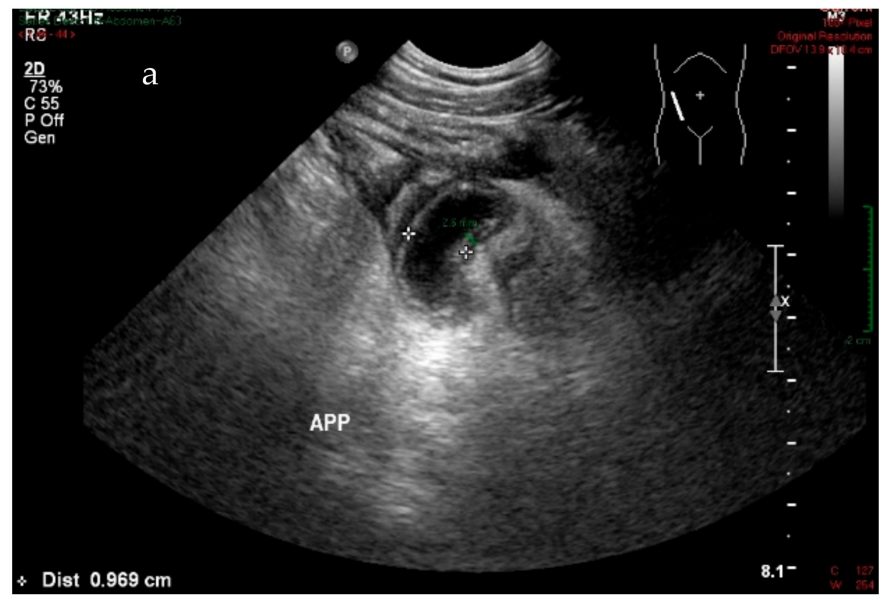

Figure 4. Cont. 


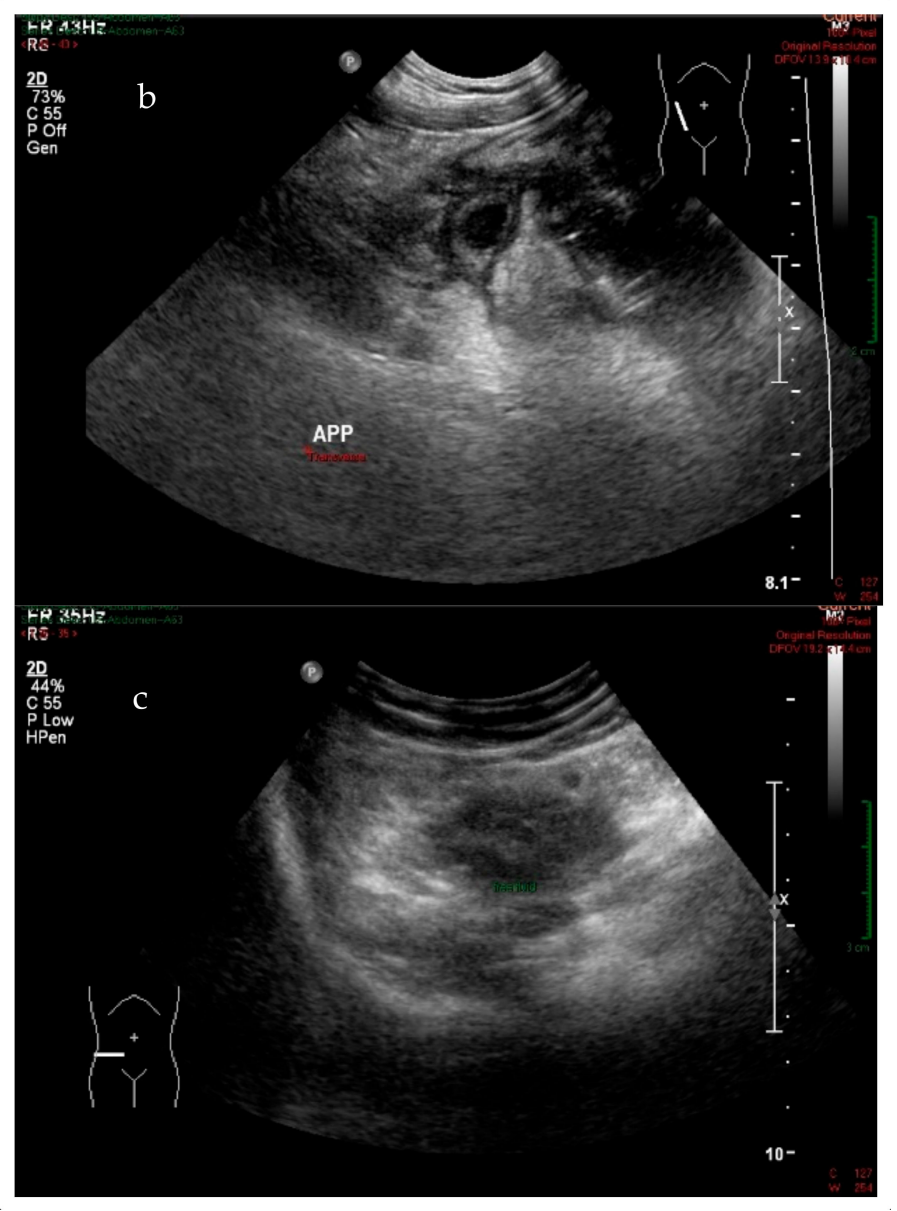

Figure 4. Longitudinal (a) and transverse (b) real-time ultrasound scan of acute appendicitis with diameter $>7 \mathrm{~mm}$ (white measure) and wall thickness $2.6 \mathrm{~mm}$ (green measure) for 33-year-old male patient with pain in the right lower quadrant; transverse (c) real-time ultrasound scan for 34-year-old female patient with suspected appendicitis shows free fluid in the right lower quadrant.

The study showed that there was no significant association between the age and sex of the patients and the accuracy of the diagnosis. However, female patients were diagnosed less accurately than male patients. These findings are in parallel with that of Paulson et al. and Al-Ajerami $[24,25,29]$. The higher number of false positives in female patients could be due to gynecological conditions (e.g., ruptured or bleeding ovarian cysts) that can mimic the signs and symptoms of acute appendicitis [30].

The insignificance of the association between sonographer years of experience and the accuracy of the diagnosis could be due to the study design, as the sample population was retrospectively retrieved from individuals who underwent an appendectomy. This study design also meant it was not possible to report any instances where US prevented unnecessary surgery by determining that the appendix was normal.

This study demonstrated that US had low sensitivity, high specificity, high PPV, and low NPV, which is also consistent with the majority of earlier studies [24,31-33]. This study also showed that US has a low diagnostic accuracy. This is in agreement with the findings of a systematic review and meta-analysis stating that the diagnostic accuracy of US is not better than that of physical examination [18]. However, the high PPV of US suggests that it could be used as a first-line test for the diagnosis of acute appendicitis. However, care should be taken when making a clinical decision, as this study showed that US was unable to identify a positive acute appendicitis in almost two-thirds of the cases. As a result, it may be better to use a CT scan in highly suspected cases to avoid the risk of severe outcomes. A previous review suggested that CT is a good choice for use as a 
confirmatory test because of its technical reproducibility and its high sensitivity (87-100\%) and specificity (89-99\%) [31].

This study has certain limitations. For example, factors that could have affected diagnostic accuracy, such as patient fasting status, the retrocecal location of their appendix, their weight, could not be taken into consideration.

It must be acknowledged that US is not a primary technique used to examine appendicitis conditions at this specific central Hospital, and our study attempts to explore the benefit of using an US technique as a first-line modality in order to decrease the use of ionizing radiation (CT). However, further studies could audit sonographer' performance thoroughly to clarify the variation in US accuracy.

\section{Conclusions}

Although this study demonstrated a low level of diagnostic accuracy when utilizing US to diagnose cases of acute appendicitis, the specificity and the PPV values were high supporting the use of US as a first-line test in the diagnosis of acute appendicitis.

Author Contributions: Conceptualization, M.A. (Magbool Alelyani), I.H., M.A. (Mohammed Alqahtani), N.S., Y.A.; methodology, I.H., M.A. (Mohammed Adam), S.A., H.A.; validation, M.A. (Magbool Alelyani), I.H., N.S., S.A.; formal analysis, M.A. (Mohammed Alqahtani), N.S., Y.A.; writing-review and editing, M.A. (Magbool Alelyani), S.A., I.H., N.S.; supervision, M.A. (Mohammed Adam), All authors have read and agreed to the published version of the manuscript.

Funding: The authors extend their appreciation for funds provided by the Deanship of Scientific Research at King Khalid University through grant number (GRP-232-40).

Institutional Review Board Statement: The study was conducted according to the guidelines of the Declaration of Helsinki, and approved by the Ethics Committee of Academic Affairs for Training and Research, Aseer Central Hospital in 26/2/2019.

Informed Consent Statement: Not applicable.

Acknowledgments: We deeply acknowledge Taif University for supporting the researchers through Taif University Researchers Supporting Project number (TURSP-2020/287), Taif University, Taif, Saudi Arabia. Moreover, authors extend their appreciation to the College of Applied Medical Sciences Research Center and Deanship of Scientific Research at King Saud University for funding this project.

Conflicts of Interest: The authors declare no conflict of interest.

\section{References}

1. Omari, A.H.; Khammash, M.R.; Qasaimeh, G.R.; Shammari, A.K.; Yaseen, M.K.B.; Hammori, S.K. Acute appendicitis in the elderly: risk factors for perforation. World J. Emerg. Surg. 2014, 9, 6. [CrossRef] [PubMed]

2. Storm-Dickerson, T.L.; Horattas, M.C. What have we learned over the past 20 years about appendicitis in the elderly? Am. J. Surg. 2003, 185, 198-201. [CrossRef]

3. Vriesman, A.C.V.B.; Puylaert, J.B.C.M. Mimics of Appendicitis: Alternative Nonsurgical Diagnoses with Sonography and CT. Am. J. Roentgenol. 2006, 186, 1103-1112. [CrossRef]

4. Cobben, L.P.; Groot, I.; Haans, L.; Blickman, J.G.; Puylaert, J. MRI for Clinically Suspected Appendicitis During Pregnancy. Am. J. Roentgenol. 2004, 183, 671-675. [CrossRef] [PubMed]

5. Wagner, P.L.; Eachempati, S.R.; Soe, K.; Pieracci, F.M.; Shou, J.; Barie, P.S. Defining the current negative appendectomy rate: For whom is preoperative computed tomography making an impact? Surgery 2008, 144, 276-282. [CrossRef]

6. Von Titte, S.N.; McCabe, C.J.; Ottinger, L.W. Delayed appendectomy for appendicitis: Causes and consequences. Am. J. Emerg. Med. 1996, 14, 620-622. [CrossRef]

7. Birnbaum, B.A.; Wilson, S.R. Appendicitis at the Millennium. Radiology 2000, 215, 337-348. [CrossRef]

8. Keyzer, C.; Zalcman, M.; De Maertelaer, V.; Coppens, E.; Bali, M.-A.; Gevenois, P.A.; Van Gansbeke, D. Comparison of US and Unenhanced Multi-Detector Row CT in Patients Suspected of having Acute Appendicitis 1. Radiology 2005, 236, 527-534. [CrossRef]

9. Townsend, C.M., Jr.; Beauchamp, R.D.; Evers, B.M.; Mattox, K.L. (Eds.) Sabiston Textbook of Surgery: The Biological Basis of Modern Surgical Practice, 20th ed.; Elsevier: Philadelphia, PA, USA, 2016.

10. Neumayer, L. Imaging in appendicitis: a review with special emphasis on the treatment of women. Obstet. Gynecol. 2003, 102, 1404-1409. [CrossRef] 
11. Larson, D.B.; Rader, S.B.; Forman, H.P.; Fenton, L.Z. Informing Parents About CT Radiation Exposure in Children: It's OK to Tell Them. Am. J. Roentgenol. 2007, 189, 271-275. [CrossRef]

12. Memon, A.A.; Vohra, L.M.; Khaliq, T.; Lehri, A.A. Diagnostic Accuracy of Alvarado Score in the Diagnosis of acute Appendicitis. Pak. J. Med. Sci. 2009, 25, 118-121.

13. Khan, U.; Kitar, M.; Krichen, I.; Maazoun, K.; Althobaiti, R.A.; Khalif, M.; Adwani, M. To determine validity of ultrasound in predicting acute appendicitis among children keeping histopathology as gold standard. Ann. Med. Surg. 2019, 38, 22-27. [CrossRef]

14. Marin, J.R.; Lewiss, R.E.; Ultrasound, W.I.N.F.O.C. Point-of-Care Ultrasonography by Pediatric Emergency Medicine Physicians. Pediatr. 2015, 135, e1113-e1122. [CrossRef] [PubMed]

15. Russell, W.S.; Schuh, A.M.; Hill, J.G.; Hebra, A.; Cina, R.A.; Smith, C.D.; Streck, C.J. Clinical Practice Guidelines for Pediatric Appendicitis Evaluation Can Decrease Computed Tomography Utilization While Maintaining Diagnostic Accuracy. Pediatric Emerg. Care 2013, 29, 568-573. [CrossRef] [PubMed]

16. Izbicki, J.R.; Wilker, D.K.; Mandelkow, H.K.; Müller, K.; Siebeck, M.; Geissler, K.; Schweiberer, L. Retro- and prospective studies on the value of clinical and laboratory chemical data in acute appendicitis. Chir. Z. Alle Geb. Oper. Medizen 1990, 61, 887-893.

17. Pinto, F.; Pinto, A.; Russo, A.; Coppolino, F.; Bracale, R.; Fonio, P.; Macarini, L.; Giganti, M. Accuracy of ultrasonography in the diagnosis of acute appendicitis in adult patients: review of the literature. Crit. Ultrasound J. 2013, 5, S2. [CrossRef]

18. Giljaca, V.; Nadarevic, T.; Poropat, G.; Nadarevic, V.S.; Stimac, D. Diagnostic Accuracy of Abdominal Ultrasound for Diagnosis of Acute Appendicitis: Systematic Review and Meta-analysis. World J. Surg. 2016, 41, 693-700. [CrossRef]

19. Puylaert, J.B.; Rutgers, P.H.; Lalisang, R.I.; De Vries, B.C.; Van Der Werf, S.D.; Dörr, J.P.; Blok, R.A. A Prospective Study of Ultrasonography in the Diagnosis of Appendicitis. N. Engl. J. Med. 1987, 317, 666-669. [CrossRef]

20. D'Souza, N.; Grant, D.; Royston, E.; Farouk, M. The value of ultrasonography in the diagnosis of appendicitis. Int. J. Surg. 2015, 13, 165-169. [CrossRef]

21. Lee, S.L.; Walsh, A.J.; Ho, H.S. Computed Tomography and Ultrasonography Do Not Improve and May Delay the Diagnosis and Treatment of Acute Appendicitis. Arch. Surg. 2001, 136, 556-562. [CrossRef]

22. Lorusso, F.; Fonio, P.; Scardapane, A.; Giganti, M.; Rubini, G.; Ferrante, A.; Ianora, A.A.S. Gatrointestinal imaging with multidetector CT and MRI. Recenti Prog. Med. 2012, 103, 493-499. [PubMed]

23. Summa, M.; Perrone, F.; Priora, F.; Testa, S.; Quarati, R.; Spinoglio, G. Integrated clinical-ultrasonographic diagnosis in acute appendicitis. J. Ultrasound 2007, 10, 175-178. [CrossRef] [PubMed]

24. Al-Ajerami, Y. Sensitivity and specificity of ultrasound in the diagnosis of acute appendicitis. East. Mediterr. Health J. 2012, 18, 66-69. [CrossRef]

25. Hussain, S.; Rahman, A.; Abbasi, T.; Aziz, T. Diagnostic accuracy of ultrasonography in acute appendicitis. J. Ayub Med Coll. Abbottabad JAMC 2014, 26, 12-17.

26. Brown, M.A. Imaging Acute Appendicitis. Semin. Ultrasound CT MRI 2008, 29, 293-307. [CrossRef] [PubMed]

27. Lee, J.H. Sonography of acute appendicitis. Semin. Ultrasound CT MRI 2003, 24, 83-90. [CrossRef]

28. Schuh, S.; Man, C.; Cheng, A.; Murphy, A.; Mohanta, A.; Moineddin, R.; Tomlinson, G.; Langer, J.C.; Doria, A.S. Predictors of Non-Diagnostic Ultrasound Scanning in Children with Suspected Appendicitis. J. Pediatrics 2011, 158, 112-118. [CrossRef] [PubMed]

29. Paulson, E.K.; Kalady, M.F.; Pappas, T.N. Suspected Appendicitis. N. Engl. J. Med. 2003, 348, 236-242. [CrossRef]

30. Gilmore, O.; Browett, J.; Griffin, P.; Ross, I.; Brodribb, A.; Cooke, T.; Higgs, M.; Williamson, R. APPENDICITIS AND MIMICKING CONDITIONS. Lancet 1975, 306, 421-424. [CrossRef]

31. Douglas, C.D.; E Macpherson, N.; Davidson, P.M.; Gani, J.S. Randomised controlled trial of ultrasonography in diagnosis of acute appendicitis, incorporating the Alvarado score. BMJ 2000, 321, 919. [CrossRef]

32. Hanafi, M.G.; Shiri, A. Retracted Article: Diagnostic Accuracy of Acute Appendicitis by Ultrasound in Hospital Emergency. Jentashapir J. Heal. Res. 2018, 9, 8787-8793. [CrossRef]

33. Van Randen, A.; Laméris, W.; Van Es, H.W.; Van Heesewijk, H.P.M.; Van Ramshorst, B.; Hove, W.T.; Bouma, W.H.; Van Leeuwen, M.S.; Van Keulen, E.M.; Bossuyt, B.M.; et al. A comparison of the Accuracy of Ultrasound and Computed Tomography in common diagnoses causing acute abdominal pain. Eur. Radiol. 2011, 21, 1535-1545. [CrossRef] [PubMed] 